\title{
Blood pressure control during maintenance haemodialysis with isonatric (high sodium) dialysate
}

\author{
William K. Stewart \\ M.D., F.R.C.P.E., M.R.C.P.
}

\author{
LAURA W. Fleming \\ B.Sc.
}

\section{Department of Medicine, University of Dundee, Scotland}

\begin{abstract}
Summary
Isonatric (high sodium) dialysis has several advantages, including relative freedom from cramps. The diastolic blood pressures and body weights of nine originally hypertensive patients on maintenance haemodialysis have been recorded for 15 months throughout alternating periods on isonatric $(145 \mathrm{mEq} / \mathrm{l})$ and low $(132.5$ $\mathrm{mEq} / \mathrm{l})$ dialysate sodium concentration. Isonatric dialysis resulted in a temporary 1-2 $\mathrm{kg}$ increase in mean pre-dialysis weight, requiring increased ultrafiltration. This coincided with a slight increase in mean pre-dialysis diastolic blood pressure which was corrected when post-dialysis body weights were lowered to compensate for the increased weight gain between dialyses. Once the 'ideal' individual post-dialysis body weight for each patient was established, pre-dialysis diastolic pressures less than $90 \mathrm{mmHg}$ were achieved routinely. Ten subsequent patients who have never received low sodium dialysis also have well controlled pressures. These findings are contrary to the orthodox view that low sodium dialysis is mandatory to avoid hypertension.
\end{abstract}

\section{Introduction}

In maintenance haemodialysis, a dialysate containing around $130 \mathrm{mEq}$ sodium/l, which induces hyponatraemia, is considered necessary for the control of both hypertension and thirst (Moriarty and Parsons, 1966; Robinson, 1969). Hypertension in chronic renal failure has been related to body sodium content (Ledingham, 1971). Comty, Rottka and Shaldon (1964) were among the first to show that, during haemodialysis, the removal of sodium and water by ultrafiltration can help to control diastolic hypertension. They, like others since (Vertes et al., 1964; Stokes, Mani and Stewart, 1970) used conventional dialysate of $130 \mathrm{mEq}$ sodium/l (Drukker, Jungerius and Alberts, 1967), combined with a diet of rigorously limited sodium content and restricted fluid intake.

Correspondence: Dr W. K. Stewart, Department of Medicine, The University, Dundee, DD1 4HN, Scotland.
Despite the use of low sodium dialysate, ultrafiltration, hypotensive drugs and restricted water and sodium intake, about one in eight patients on maintenance haemodialysis are said to have refractory hypertension (Vertes et al., 1964; Anonymous, 1969; Stokes et al., 1970; Strangfeld et al., 1971). As many as five out of thirteen patients have been found to be resistant (Safar et al., 1970). For these resistant hypertensive patients, bilateral nephrectomy continues to be recommended (Papadimitriou, Chisholm and Shackman, 1969; Mahones et al., 1972; Lazarus et al., 1972) the only current alternative being long-term treatment with hypoe tensive drugs such as diazoxide (Pohl and Thurston; 1972).

Earlier work has shown that our patients have fewer episodes of vomiting and 'disequilibrium', and maintain normal plasma sodium concentrations, during the use of what is by conventional standards high sodium, but in essence, physiologically isonatric, dialysis (Stewart, Fleming and Manuel, 1972a; Fleming and Stewart, 1972). Perhaps most welcome from the patient's point of view is the relative freedom from cramp during and after such isonatric dialysis (Stewart, Fleming and Manuel, 1972b).

It appears that the major reason preventing others from using a higher sodium strength lies in the fear of aggravating incipient hypertension. The results described here demonstrate that, in patients on maintenance haemodialysis, most of whom were originally hypertensive, the use of a dialysate sodium concentration of $145 \mathrm{mEq} / \mathrm{l}$, combined with enhanced ultrafiltration, is compatible with good blood pressure control, with only minimal dietary fluid or sodium restriction and without any antihypertensive drugs.

\section{Patients and methods}

Over a period of $2 \frac{1}{2}$ years nineteen patients have been dialysed twice weekly for a total of 16-22 hr/ week with isonatric dialysate as itemized below. Patients were not selected. All patients in the Unit 
have been treated as described and no patients so treated have been omitted from this report.

The first seven patients were originally studied for 15 months, divided into four consecutive phases. During phases 1 and 3 (3 months duration each) dialysis-fluid containing $132.5 \mathrm{mEq}$ sodium/l (low sodium) was used. During phases 2 ( 5 months) and 4 (4 months), and subsequently, the dialysate sodium concentration was $145 \mathrm{mEq} / \mathrm{l}$ (isonatric). The patients were not informed when the dialysate sodium changes were made. Prior to the study, the seven patients had been on maintenance haemodialysis with low sodium dialysate for periods ranging between 5 and 17 months. Two of these had failed renal transplants and one of the latter was totally nephrectomized. Another patient (DW) joined the programme towards the end of phase 2 and received a transplant in the middle of phase 4. A ninth patient began during phase 3 . All ten subsequent patients entered the maintenance dialysis programme either during or after the end of phase 4, and have never received low sodium dialysis. They have been dialysed for periods varying between 2 and 19 months.

\section{General treatment}

Antihypertensive drugs were never used during the span of this investigation, although all patients (except two 'salt-losers') received such drugs before maintenance dialysis therapy was instituted. The original seven patients did receive some antihypertensive drug treatment during their first few months of low sodium dialysis, prior to this investigation. The diet consisted of $80 \mathrm{~g}$ protein daily with a sodium intake of $20-50 \mathrm{mEq}$ daily and only a general admonition to reduce fluid intake as much as possible.

Dylade dialysate supply units were used with Travenol 'Ultra-flo 100' disposable coils. 'Ultra-flo 145' coils were used for 2 weeks during phase 4 for five of the patients, in order to progressively reduce body weight by enhanced ultrafiltration. Weekly measurements of isonatric dialysate gave a mean sodium value ( \pm s.d.) of $146 \pm 2 \mathrm{mEq} / \mathrm{l}$. A closed container system for negative pressure dialysis (Wakefield, Stewart and Goddard, 1970) effected the enhanced rates of ultrafiltration required during isonatric dialysis. Ultrafiltration was measured by the body weight change during dialysis using a weighing-bed.

The standard ' $t$ ' test for paired data was used where appropriate (Dunn, 1964), i.e. for 'within phase' comparisons where the number of patients was the same. When the mean results for eight patients (phases 3 and 4) were compared with those for seven patients (phases 1 and 2) the standard Student's ' $t$ ' test for unpaired data was used.

\section{Results}

\section{Mean blood pressures and body weight}

The mean pre-dialysis diastolic pressures of the seven original patients who had been dialysed prior to the period of study was $113 \mathrm{mmHg}$ (extreme range 99-131) during their first eight dialyses.

The mean pre- and post-dialysis diastolic blood pressures during the different phases are shown (Table 1), together with the corresponding mean body weights. Mean diastolic pressure levels for patient DW, who underwent renal transplantation during phase 4 before adequate blood pressure control could be achieved, varied between 109 and 113 $\mathrm{mmHg}$ but were no higher during isonatric dialysis. His results are omitted from the means shown since they were at all times well outside the range for the other patients. The results for phases 2 and 4 are divided into (a) early (first 2 months), and (b) late period (last 2 months), since diastolic pressures were invariably lower during the second half of each of these phases. Mean post-dialysis diastolic pressures were consistently lower than pre-dialysis by 10-15 $\mathrm{mmHg}$, but were not in the symptomatic hypotensive range.

\section{Changes during the phases}

The mean diastolic pressure on low sodium dialysis during phase 1 includes the values for two patients whose pressure had never previously yielded to ultrafiltration and who then presented routinely predialysis with diastolic pressures ranging between 110 and $140 \mathrm{mmHg}$. During the first 2 months of phase 2 , on isonatric dialysis, the mean pre-dialysis pressure increased by $7 \mathrm{mmHg}$ (statistically insignificant). The mean pre-dialysis body weight increased due to an increase in the weight gain between dialysis. The post-dialysis weights of all the patients were therefore deliberately decreased by temporarily augmenting ultrafiltration further and subsequently the pre-dialysis body weight during the last 2 months of phase 2 returned to its previous level of around $60 \mathrm{~kg}$. A decrease in mean predialysis diastolic pressure followed $(P<0.025)$. In phase 3 , the repeat phase on low sodium dialysis, the mean pre-dialysis pressure was marginally lower at $84 \mathrm{mmHg}$, with no change in mean pre-dialysis weight. A similar pattern was seen during phases 3 and 4. Relatively increased ultrafiltration was again employed during each isonatric dialysis.

\section{Adjustment of body weight}

It was decided in the middle of phase 4 that predialysis diastolic pressures exceeding $90 \mathrm{mmHg}$ should be considered unacceptable. Five patients came into this category. During a 2-week period an effort was made to reduce progressively the pre- and 
TABle 1. Mean pre- and post-dialysis body weights and diastolic blood pressures ( \pm s.d.)

\begin{tabular}{|c|c|c|c|c|c|}
\hline Phase & $\begin{array}{l}{[\mathrm{Na}]_{d}} \\
(\mathrm{mEq} / \mathrm{l})\end{array}$ & $\begin{array}{l}\text { No. of } \\
\text { patients }\end{array}$ & $\begin{array}{l}\text { Measurement } \\
\text { (time) }\end{array}$ & $\begin{array}{l}\text { Body wt. } \\
\text { (kg) }\end{array}$ & $\begin{array}{c}\text { Diastolic } \\
\text { B.P. } \mathrm{mmHg}\end{array}$ \\
\hline 1 & 132 & $7 \mathrm{E}$ & $\begin{array}{l}\text { pre } \\
\text { post }\end{array}$ & $\begin{array}{l}59 \cdot 8 \pm 6 \cdot 1 \\
57 \cdot 3 \pm 2 \cdot 5\end{array}$ & $\begin{array}{l}95 \pm 10 \\
80 \pm 8\end{array}$ \\
\hline 2(a) & 145 & $7 \mathrm{E}$ & $\begin{array}{l}\text { pre } \\
\text { post }\end{array}$ & $\begin{array}{l}60 \cdot 8 \pm 6 \cdot 3 \\
56 \cdot 5 \pm 6 \cdot 0\end{array}$ & $\begin{array}{r}102 \pm 11 \\
85 \pm 11\end{array}$ \\
\hline 2(b) & 145 & $7 \mathrm{E}$ & $\begin{array}{l}\text { pre } \\
\text { post }\end{array}$ & $\begin{array}{l}60.0 \pm 6.9 \\
55.6 \pm 6.6\end{array}$ & $\begin{array}{l}91 \pm 7 \\
76 \pm 10\end{array}$ \\
\hline 3 & 132 & $8 \mathrm{E}$ & $\begin{array}{l}\text { pre } \\
\text { post }\end{array}$ & $\begin{array}{l}60.0 \pm 7.6 \\
57.4 \pm 7 \cdot 1\end{array}$ & $\begin{array}{l}84 \pm 7 \\
74 \pm 9\end{array}$ \\
\hline $4(a)$ & 145 & $8 \mathrm{E}$ & $\begin{array}{l}\text { pre } \\
\text { post }\end{array}$ & $\begin{array}{l}61 \cdot 9 \pm 8.4 \\
57 \cdot 8 \pm 7 \cdot 8\end{array}$ & $\begin{array}{l}90 \pm 7 \\
80 \pm 6\end{array}$ \\
\hline $4(b)$ & 145 & $8 \mathrm{E}$ & $\begin{array}{l}\text { pre } \\
\text { post }\end{array}$ & $\begin{array}{l}60 \cdot 1 \pm 7 \cdot 5 \\
56 \cdot 1 \pm 7 \cdot 0\end{array}$ & $\begin{array}{l}81 \pm 6 \\
73 \pm 7\end{array}$ \\
\hline $\begin{array}{l}16 \text { months later* } \\
\text { (June 1973) }\end{array}$ & $\begin{array}{c}\text { Continuing } \\
\text { on } \\
145\end{array}$ & $5 \mathrm{E}$ & $\begin{array}{l}\text { pre } \\
\text { post }\end{array}$ & $\begin{array}{l}61 \cdot 0 \pm 7 \cdot 5 \\
56 \cdot 7 \pm 6.9\end{array}$ & $\begin{array}{l}84 \pm 8 \\
77 \pm 10\end{array}$ \\
\hline First eight dialyses & 145 & $10 \mathrm{~N}$ & $\begin{array}{l}\text { pre } \\
\text { post }\end{array}$ & $\begin{array}{l}63 \cdot 0 \pm 12 \cdot 3 \\
60 \cdot 5 \pm 11 \cdot 8\end{array}$ & $\begin{array}{l}97 \pm 14 \\
83 \pm 11\end{array}$ \\
\hline $\begin{array}{c}\text { Eight most recent } \\
\text { dialyses }\end{array}$ & 145 & $10 \mathrm{~N}$ & $\begin{array}{l}\text { pre } \\
\text { post }\end{array}$ & $\begin{array}{l}63 \cdot 8 \pm 14 \cdot 5 \\
60 \cdot 4 \pm 13 \cdot 7\end{array}$ & $\begin{array}{l}84 \pm 5 \\
73 \pm 7\end{array}$ \\
\hline
\end{tabular}

(a) First two months of phase; (b) last two months of phase; * mean results for eight most recent dialyses, only five patients remain since others transplanted in past year; $E$, patients already established on maintenance dialysis at $[\mathrm{Na}]_{\mathrm{d}}=132 \mathrm{mEq} / \mathrm{l}$ prior to the investigation; $\mathrm{N}$, 'new' patients who have never received low sodium dialysis.

post-dialysis weights of these five patients by even more intensive ultrafiltration. A temporarily increased incidence of cramps occurred during these four or five dialyses. Transient nausea and hypotension, requiring raising of the foot of the dialysisbed, often, but not invariably, preceded the cramps. The mean body weights of these five patients were successfully reduced in 2 weeks by between 2 and 6 $\mathrm{kg}$ (Fig. 1). The net result of the progressively increased ultrafiltration was that the mean pre-dialysis body weight of the eight established patients for the last 2 months of phase 4 returned to $60 \mathrm{~kg}$ and the mean diastolic pressure $( \pm$ s.d.) was further reduced to $81 \pm 6 \mathrm{mmHg}(P<0.01$ compared with low sodium dialysis in phase 1). The relationship between blood pressure and body weight during isonatric dialysis is illustrated further in Fig. 2, which shows the mean diastolic pressures and body weights before and after weight reduction in the five patients mentioned above. The positive correlation is evident.

\section{Follow-up period}

Since the end of phase 4 (16 months ago) there has been no change in the established blood pressure/ body weight pattern. During their eight most recent dialyses the mean pre-dialysis diastolic pressure for the remaining five of the original nine patients (four have now received renal transplants) was $84 \pm 8$ (s.d.) $\mathrm{mmHg}$.

The mean pre-dialysis diastolic pressures for the first eight (isonatric) dialyses of the ten new patients was $97 \mathrm{mmHg}$ (extreme range 81-125) whereas the corresponding mean pressure for their most recent eight dialyses has been $84 \mathrm{mmHg}$ (extreme range 75-91). During the initial adjustments, some patients had mild hypotensive effects if the post-dialysis weight had been taken too low, or if the ultrafiltration rate used had exceeded $1 \mathrm{l} / \mathrm{hr}$, but any $\mathrm{\omega}$ accompanying ill-effects were tolerable, brief and $\sigma_{-}$ reversible if necessary by saline administration, $\bullet$ and the patients could always return home normally. In practice remedial saline administration has been used in less than $8 \%$ of the initial dialyses, and has become progressively less often used as the Nursing Staff have gained experience of the isonatric-ultrafiltration technique. 


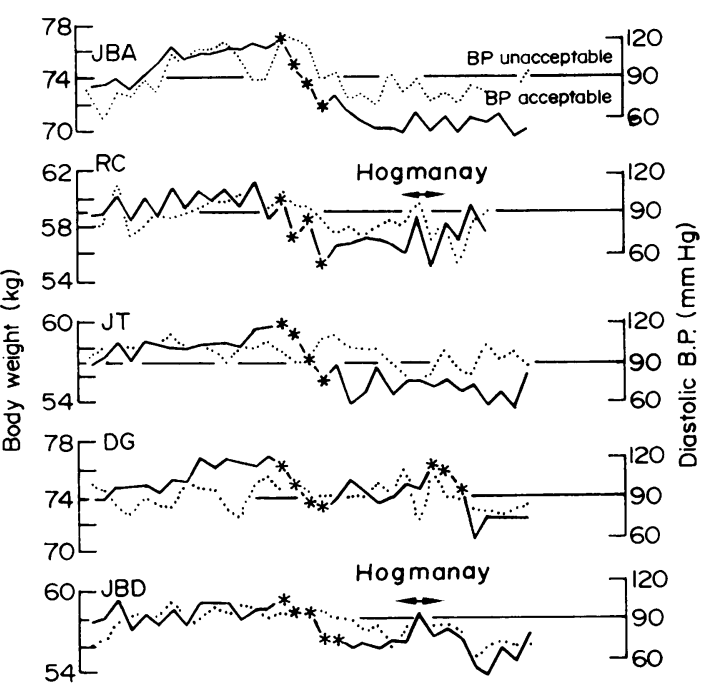

FIG. 1. Correlation between individual pre-dialysis body weights and diastolic blood pressures in five patients during phase 4 . The asterisk represents the period of progressive weight reduction (Hogmanay is the Scottish New Year celebration). - , body weight (pre-dialysis); - - -, diastolic B.P.

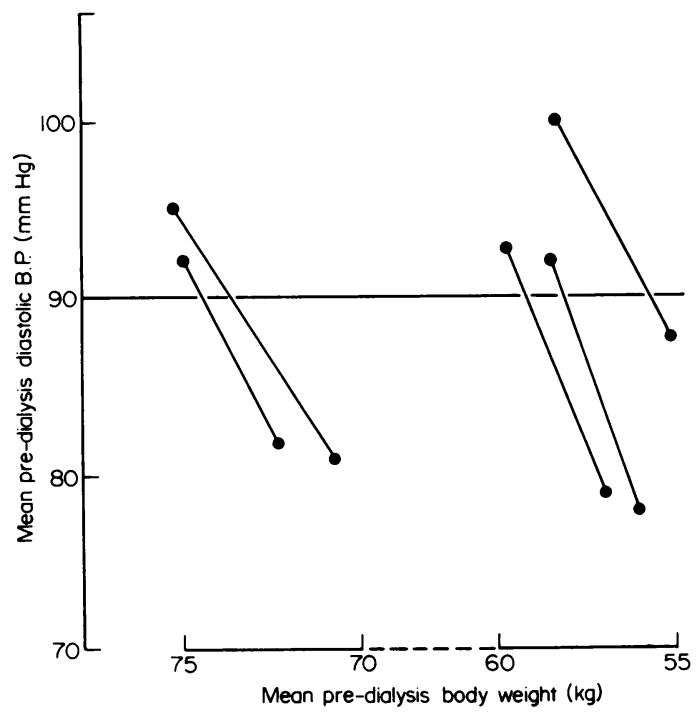

FIG. 2. Relationship between mean pre-dialysis body weight and diastolic blood pressure for five patients before and after weight reduction during isonatric dialysis (phase 4).

\section{Discussion}

These results suggest that, contrary to orthodox expectations, isonatric dialysis is capable of longterm use without the development of progressive diastolic hypertension. Out of a total of nineteen patients, eighteen have responded well and now routinely present pre-dialysis with diastolic pressures less than $90 \mathrm{mmHg}$. Unfortunately, from the viewpoint of this study, the one exception experienced only 3 months of isonatric dialysis and received a renal allograft before full control was achieved. Low sodium dialysis also failed to control his diastolic hypertension, which was in fact marginally lower during isonatric dialysis.

We define the 'ideal' body weight for each patient as the post-dialysis weight which permits them to present 3 days later with pre-dialysis diastolic pressures less than $90 \mathrm{mmHg}$. The satisfactory diastolic pressures observed once 'ideal' weights were achieved indicate that the control of blood pressure by ultrafiltration is as applicable to isonatric dialysis as it is to low sodium dialysis (Comty et al., 1964). Isonatric dialysis combined with enhanced ultrafiltration has the added advantage that oral fluid intake need not be restricted unduly. Our patients show between dialyses a mean weight gain of $4 \mathrm{~kg}$ and they enjoy the increased freedom to drink more, without any complaint of actual thirst. Although we discourage inter-dialysis weight gain in excess of $5 \mathrm{~kg}$, it is practicable, using the negative pressure system, to remove 61 each dialysis if indicated. While on isonatric dialysis this amount of ultrafiltration can readily be tolerated without cramps (Stewart et al., 1972b) or other obvious ill-effects (Stewart et al., 1972a). Likewise sodium intake need not be unduly restricted other than by an injunction to 'avoid added salt'. Antihypertensive drugs have not been required.

We are not at present advocating that dialysists should use isonatric dialysis for the primary reason of improving control of hypertension. However, in view of the other obvious benefits of isonatric dialysis (Stewart et al., 1972a), the routine use of isonatric dialysis is to be recommended. Two of the original patients formerly resistant to control of hypertension while on low sodium dialysis are now in good control $(<90 \mathrm{mmHg})$ and one of the new patients who presented with diastolic pressures of $140 \mathrm{mmHg}$ is also now in good control. Other authors cited have met a much higher 'failure' rate when attempting to control hypertension using conventional low sodium dialysis. We should like to re-emphasize that, contrary to general expectation, control of hypertension has proved perfectly feasible during isonatric dialysis. Indeed, it was the failure to adequately control hypertension during low sodium dialysis which in part led us to try isonatric dialysis in the first place. There have been reports in the literature (e.g. Craswell et al., 1972) to show that plasma renin activity in dialysed patients is inversely related to plasma sodium concentrations. Low sodium dialysis is associated with appreciably lower plasma sodium 
levels compared with isonatric dialysis (Fleming and Stewart, 1972).

In conclusion, in view of the current recommendations of bilateral nephrectomy for refractory hyertension (Mahoney et al., 1972; Lazarus et al., 1972) and the fact that opponents of bilateral nephrectomy (Pohl and Thurston, 1972) can only resort to imperfect drug therapy, a method such as isonatric dialysis with appropriate ultrafiltration, which also provides considerable other benefits for the patient, warrants further trial. We appreciate that at a total of nineteen, our patient numbers are still small, but all experience to date suggests that, stated conservatively, at least some of the patients with previously refractory hypertension yield to this approach. The concepts underlying the current advocacy of low sodium dialysis may need to be re-considered. Our results do show that the use of conventional low sodium dialysis is not mandatory for good blood pressure control.

\section{References}

Compty, C., Rottka, H. \& Shaldon, S. (1964) Blood pressure control in patients with end-stage renal failure treated by intermittent haemodialysis. Proceedings of the European Dialysis and Transplant Association, 1, 209.

Craswell, P.W., Hird, V.M., Judd, P.A., Baillod, R.A., VARghese, Z. \& Moorhead, J.F. (1972) Plasma renin activity and blood pressure in eighty-nine patients receiving maintenance haemodialysis therapy. British Medical Journal, 4, 749.

Drukker, W., Jungerius, N.A. \& Alberts, C. (1967) Report on regular dialysis treatment in Europe III. Proceedings of the European Dialysis and Transplant Association, 4,3 .

DunN, O.J. (1964) Basic Statistics: A Primer for the Biomedical Sciences, p. 73. John Wiley and Sons, Inc.: New York.

Fleming, L.W. \& Stewart, W.K. (1972) The experimental use of high sodium strength dialysate in the treatment of end-stage renal failure (Abstract). Scottish Medical Journal, 17, 375.
Lazarus, J.M., Hampers, C.L., Bennett, A.H., Vandam, L.D. \& MERRILL, J.P. (1972) Urgent bilateral nephrectomy $\varrho$ for severe hypertension. Annals of Internal Medicine, 76,. 733.

LEADING ARTICLE (1969) Hypertension in patients on regular dialysis. British Medical Journal, 3, 669.

LEDINGHAM, J. (1971) Blood pressure regulations in renal failure. Journal of the Royal College of Physicians (London), 5, 103.

Mahoney, J.F., Storey, B.G., Gibson, G.R., Stokes, G.S., $\stackrel{\unrhd}{\unrhd}$ SheIL, A.G.R. \& STEWART, J.H. (1972) Bilateral nephrec- শి tomy for malignant hypertension. Lancet, i, 1036.

Moriarty, M.V. \& Parsons, F.M. (1966) Hypernatraemia $\vec{\circ}$ during peritoneal dialysis. Proceedings of the European Dialysis and Transplant Association, 3, 359.

Papadimitriou, M., Chisholm, G.D. \& Shackman, R. (1969) Hypertension in patients on regular haemodialysis and after renal allotransplantation. Lancet, i, 902.

Poht, J.E.F. \& Thurston, H. (1972) Bilateral nephrectomy for malignant hypertension. Lancet, i, 1231.

RoBINson, B. (1969) Report on Water Requirements for Kidney Dialysis, p. 13. Elga Group of Companies, London.

Safar, M., Fendler, J.P., Weil, B., BeuVe-Mery, P., $\omega$ Brissett, J.M., Idatte, J.M., Meyer, P. \& Milliez, P. ᄋ (1970) Hypertension in patients on maintenance haemodialysis. Revue Européen d'études cliniques et biologiques, 윽 $15,740$.

SteWART, W.K., Fleming, L.W. \& Manuel, M.A. (1972a) Benefits obtained by the use of high sodium dialysate during maintenance haemodialysis. Proceedings of the European Dialysis and Transplant Association, 9, 111.

Stewart, W.K., Fleming, L.W. \& Manuel, M.A. (1972बి Muscle cramps during maintenance haemodialys : Lancet, i, 1049.

Stokes, G.S., Mani, M.K. \& Stewart, J.H. (1970) Relevance्e of salt, water and renin to hypertension in chronic renál failure. British Medical Journal, 3, 126.

Strangfeld, Von D., Buchali, K., Dutz, W. \& Precht, K. (1972) Die behandlung der hypertonie bei chronischen dialysepatienten mit ultrafiltration und natriumentzug. $\overrightarrow{\vec{B}}$ Deutsches Gesundheitswesen, 26, 1140.

Vertes, V., Cangiano, J.L., Berman, L.B. \& Gould, A. (1969) Hypertension in end-stage renal disease. New England Journal of Medicine, 280, 978.

Wakefield, W.C., Stewart, W.K. \& Goddard, J.D. (1970) Negative pressure ultrafiltration in haemodialysis using a new coil-dialyser container. Biomedical Engineering, 5, 330. 